\title{
FIBRINOGEN DEFICIENCY AS A FACTOR IN HAEMORRHAGIC DISEASE
}

\author{
BY \\ E. C. Allibone. M.D., M.R.C.P., and H. S. BAAR, M.D., Ph.D. \\ (From the Children`s Hospital, Birmingham, and the Department of Paediatrics, University \\ of Birmingham)
}

Three local factors are concerned with arrest of haemorrhage. Magnus (1924) was the first to describe the contraction of the capillaries following injury and considered this to be the initial stage in the arrest of haemorrhage. Secondly, platelets are deposited on the damaged areas of capillary endothelium where they act as protective agents, forming a platelet thrombus, which, however, does not form a firm clot. This is seen in haemophilia where, in spite of a normal bleeding time, gentle squeezing causes renewed bleeding even after some hours (Frank, 1925: Baar, 1928). Finally, thrombokinase is liberated from disintegrated platelets and damaged tissue cells and in the presence of calcium converts prothrombin to thrombin, which in turn interacts with the fibrinogen of the plasma to form fibrin. Thus a firm thrombus is formed and the capillaries are efficiently occluded.

These factors are on the one hand interdependent. e.g. the agglutination of platelets, their disintegration and liberation of thrombokinase: on the other hand there can be, as has been pointed out by one of us (Baar. 1934), a compensation of one deficient factor by another. This can best be seen from the experiments of Roskam (1921), who produced by intravenous gelatin injections either a reduction of platelets, an incoagulability of blood or both together. The bleeding time was moderately prolonged in the first instance, normal in the second, but very considerably prolonged in the third.

At various times one or other of these factors has been the focus of attention. Recently the prothrombin content of the plasma has been in the foreground, particularly with regard to the haemorrhagic diathesis, and has tended to overshadow other factors so that haemorrhagic disease of the newborn is often considered to be synonymous with prothrombin deficiency. Although prothrombin deficiency (quantitative or qualitative) without doubt is present in haemorrhagic disease of the newborn, the mechanism of the haemorrhage is not so simple as it would appear from recent papers.

From time to time cases have been reported in which a haemorrhagic tendency was associated with a complete failure of the blood to clot and a reduction or absence of blood fibrinogen.

\section{Review of the literature}

The first case was described by Rabe and Salomon (1920) and was followed up four years later by Breckoff (1924). The patient, a boy aged thirteen in 1924 had bled periodically into the skin and had bruised easily since birth. During the symptomatic phases the bleeding time was raised to at least fortyeight hours, but was reduced to five minutes following blood transfusion. The blood, however, never clotted in vitro and at no time was fibrinogen detected in the blood. To explain the periodicity of symptoms an unknown alteration in the vessels was postulated as the other factor necessary for haemorrhage.

Opitz and Frei (1921) then reported a fatal case in an eight-month-old female infant who had had haemorrhage from the stomach and bowel since birth. No factor inhibiting blood coagulation could be demonstrated and in addition to the absence of fibrinogen the platelets were reduced to 114,000 per c.mm.

In both the above cases the haemorrhagic tendency had dated from birth. Opitz and Silberberg (1924) now described a fatal case of generalized tuberculosis in a girl of three, who a few days before death became icteric, developed petechial haemorrhages in the skin and bled from the mouth and bowel. An attempt to elicit the patellar reflexes produced large ecchymoses over both knees. The blood did not clot within fourteen days: fibrinogen was absent. No antithrombin could be demonstrated, and blood taken from the heart immediately after death showed only 14,600 platelets per c.mm. As at autopsy the liver was found to be riddled with caseous nodules: this organ was considered to be the source of fibrinogen. The thrombopenia was attributed to the effect of toxic liver products on the megakaryocytes and the bruising to increased fragility of the vessels.

Knauer (1927) recorded what he considered to be a case of purpura fulminans occurring in a previously healthy girl of six during the course of a mild attack of varicella. The skin became covered with ecchymoses the size of tea plates, there was haematuria and bleeding from the rectum. The bleeding time was normal but the blood failed to clot after three days. The blood fibrinogen was $0.015 \mathrm{gm}$. per cent. (normal 0.22-0.36 gm. per cent.). The platelets were 196,000 per c.mm. Following two transfusions of 180 c.c. and 120 c.c. of maternal blood the fibrinogen rose within four days to $0 \cdot 27$ 146 
Convalescence was uneventful. In view of the absence of liver damage it was assumed that the fibrinogenopenia was due to temporary damage to the reticulo-endothelial system.

The case of Jürgens and Trautwein (1930) is of importance as suggesting an alternative source to the liver for the formation of fibrinogen. A fiftytwo-year-old man gave a month's history of backache. anorexia and haemorrhage from nose, gums and bladder. The bleeding time was 30 minutes, there was no clotting after forty-eight hours. The blood fibrinogen was estimated to be less than $0 \cdot 10$ gm. per cent. (except terminally $0.25 \mathrm{gm}$. per cent.). Following a blood transfusion the bleeding time fell to $2 \frac{1}{2}$ minutes but the clotting time remained unchanged. Thrombin was formed in the blood in normal amounts. He died a month later from haemorrhage. Autopsy showed a carcinoma of the prostate with extensive bone marrow metastases. The liver showed subcapsular deposits but histologically was of normal structure.

An hereditary factor was first shown by Risak (1935). Under the title constitutional fibrinopenia four cases in adults were published. The first case was that of a woman aged forty-one years who had bled from the gums and following slight trauma since girlhood. The blood fibrinogen was $0.018 \mathrm{gm}$. per cent., the platelets 144,000 per c.mm. Her son had a blood fibrinogen of $0.02 \mathrm{gm}$. per cent. In the second case a woman of twenty-two years gave a history of extensive bleeding from the skin and mucous membranes. The blood fibrinogen was $0.019 \mathrm{gm}$. per cent. and the platelets were 99,000 per c.mm. The mother had 58,000 platelets per c.mm. and a brother a clotting time of 13 minutes. The female members of the family had a haemorrhagic diathesis. The third case, a woman of seventy-one, had bled easily on injury since childhood. The blood fibrinogen was $0.018 \mathrm{gm}$. per cent.. platelets 120.000 per c.mm., bleeding time $4 \frac{1}{2}$ minutes, clotting time 4 to 12 minutes. A son had a haemorrhagic diathesis.

The last case, also a woman aged thirty-seven years. had had menorrhagia since puberty and had had a haematemesis. Her fibrinogen was 0.018 gm. per cent., platelets 400,000 per c.mm., bleeding time 3 minutes, clotting time 5 minutes. The last two cases are remarkable in having a relatively normal clotting time with a low blood fibrinogen. Owing to the association of fibrinogenopenia with thrombopenia it was felt that the bone marrow played a particular rôle in the formation of fibrinogen.

A year later Wolff (1936) described a male infant aged four weeks, who developed bruising, anaemia and jaundice. Bleeding and clotting times were in the order of hours, platelets 296,000 per c.mm. fibrinogen $0.015 \mathrm{gm}$. per cent. Death occurred after a fortnight. Autopsy showed a greenishyellow liver with no visible lobulation. A familial tendency to bleed was indicated by three sibs having died, each at the age of one year of "blood spots."

The first case in the English literature was that of MacFarlane (1938) who investigated a boy aged seven with intermittent haemorrhage since birth. The bleeding time was 30 minutes, there was no clotting within three weeks, and platelets were 110,000 per c.mm. No fibrinogen was detected in the blood. The addition of fibrinogen and thrombin to the patient's plasma and to control serum caused coagulation within $2 \frac{1}{2}$ minutes in both cases, from which the absence of any anti-coagulant was deduced. However, on adding fibrinogen to the patient's plasma, clotting took two hours as against sixteen minutes with control serum, which suggested that the formation of thrombin was also deficient. There was a strong family history. The father had a fibrinogenopenia (0.075 gm. per cent.), one sib had bled to death when ten days old and another had bled excessively following circumcision though his fibrinogen was normal. The parents were cousins. When seen a year later there was still no fibrinogen in the blood, though the platelets had risen to 425,000 per c.mm. and the bleeding time had fallen to $5 \frac{1}{2}$ minutes.

Schönholzer (1939) reported two cases. one seen by himself, the other by Fritzsche. He reviewed the literature. His case was that of a boy of twelve with a haemorrhagic diathesis since birth. He was admitted following a haematemesis and was so ill as to need immediate transfusion receiving 600 c.c. blood, after which the bleeding time was 30 minutes, clotting time $3 \frac{1}{4}$ minutes. platelets 285,000 per c.mm. Within three weeks the blood had ceased to clot. He remained well for nine months when he was re-admitted with recurrent bleeding, received 350 c.c. blood after which the bleeding time was $2 \frac{1}{4}$ minutes, clotting time $4 \frac{3}{4}$ minutes, platelets 84.000 per c.mm. Thereafter the platelet count rose to 426,000 per c.mm. and the clotting time to infinity. No other abnormality in the blood was detected. Eighteen months later he was re-admitted with a fatal cerebral haemorrhage. The platelets were 334.000 per c.mm., the blood did not clot and contained no fibrinogen.

The case of Fritzsche was that of a girl aged two and a half who, having bled and bruised easily since birth, died from haemorrhage. Her blood did not clot; platelets were 180,000 per c.mm. No fibrinogen estimations were made. It was pointed out that small amounts of fibrinogen (it would be preferable to say blood) were sufficient to arrest haemorrhage. The amount of blood given in the first case was calculated to raise the fibrinogen to not more than $0.06 \mathrm{gm}$. per cent.

Schönholzer divided cases into congenital and acquired. The latter were secondary to some infective or toxic agent acting on the site of fibrinogen formation, which was considered to be the bone marrow. The congenital cases were further subdivided into congenital fibrinogenopenia, in whom the prognosis was good, and congenital afibrinogenaemia with a poor prognosis as regards longevity. Both congenital forms were hereditary; heterozygotic cases were supposed to produce fibrinogenopenia, homozygotic cases afibrinogenaemia. The factor was recessive, the condition occurring through the marriage of relatives, which explained its rarity. If, however, heterozygotic cases have to show some fibrinogenopenia, a certain ${ }^{~}$ penetration power ${ }^{\circ}$ of the factor must be assumed; in other words the inheritance is not purely recessive but intermediate.

Glanzmann, Steiner and Keller (1940) described two cases, one congenital, the other acquired. The former was a boy of three with a haemorrhagic diathesis since birth. Admitted with traumatic bleeding from the mouth, the bleeding time was 5 minutes, clotting time more than twenty-four hours, platelets 35,000 per c.mm., fibrinogen absent. Haemorrhage was controlled with vitamins $C$ and $\mathrm{K}$ and calcium gluconate. The acquired case was an eight-month-old female infant who developed a haemorrhagic diathesis in association with a 
haemolytic anaemia, the liver and spleen being enlarged. The bleeding time was in the order of days, as was the clotting time. The platelets ranged between 187,000 and 116,000 per c.mm. The blood fibrinogen was absent, re-appearing slowly after treatment with vitamins $C$ and $K$, calcium gluconate, congo red, campolon and citrated calf plasma by mouth.

It was concluded that two types of fibrinogen lack existed, congenital and acquired. In the former the deficiency was absolute and persistent, being associated with complete inability of the blood to clot and at times a transient thrombopenia. Attacks of bleeding occurred from time to time, due to trauma or to an unknown factor, large haematomata typically being formed. In the acquired variety the deficiency of fibrinogen was transient, was, according to these authors, associated with liver damage and the haemorrhages took a band-like pattern. Thrombopenia might also occur.

In view of the comparative rarity of cases of fibrinogenopenia and the divergent opinions as to its aetiology it was felt the following two cases were worthy of record.

\section{Case reports}

Case 1. History. M. E. R., a female infant, weighed $8 \mathrm{lb}$. when born on October 8,1941 . The mother was a primipara aged thirty-three. The pregnancy and labour were normal. The baby seemed to be normal at birth and took milk feeds well. After a few days she became fretful and refused to suck. About the ninth day she gradually became quiet though she seemed to be "jumpy.' As she still did not feed she was admitted on the twelfth day (October 20, 1941) weighing $5 \mathrm{lb} .6 \mathrm{oz}$.

EXAMINATION. The baby appeared wasted and lifeless. The eyes were kept open, the pupils were small and reacted sluggishly to light. There was a variable squint; the eyelids twitched from time to time. The fontanelle was small but tense. A little blood oozed from the umbilicus. Temperature $97^{\circ} \mathrm{F}$., pulse 130 , respirations 40 per minute.

Lumbar puncture gave a blood stained fluid.

BLOOD PICTURE.

Hæmoglobin 56 per cent. Platelets 50,000 per c.mm.

Red blood cells 5,030,000 per c.mm. Haematocrit 48 per cent. Mean corpuscular volume $96 \mu^{3}$.

White blood cells 12,750 per c.mm.

Differential count:

Neutrophil myelocytes 1 per cent.

Neutrophil meta-myelocytes 2 per cent.

Neutrophil polymorphs, non-segmented 4 per cent.

Neutrophil polymorphs, segmented 11 per cent. Lymphocytes 74 per cent.

Monocytes 6 per cent.

Plasma cells 2 per cent.

Only giant platelets were present in the film.

Bleeding time 77 seconds.

Clotting time (capillary tube method): No clotting after 18 minutes.

Prothrombin time (one stage method):

Patient-No coagulation after 4 hours. (Control 22 seconds):

Serum albumin $4 \cdot 17 \mathrm{gm}$. per cent. Blood fibrinogen $0 \cdot 11 \mathrm{gm}$. per cent.
Serum globulin 1·10 gm. per cent. Blood calcium $8 \cdot 10 \mathrm{mgm}$. per $100 \mathrm{cc}$.

On the day after admission large bruises appeared on the cheeks. Death occurred on the third day after admission.

AUTOPSY. On opening the skull there was a large amount of blood over the whole of the left vertex, over the right frontal lobe and on the median surface of the left hemisphere. There were no tentorial tears, but between the two tentorial layers on the left side were multiple lentil-sized haemorrhages. A considerable part of the right occipital lobe was destroyed by haemorrhage and numerous subependymal petechiae were situated in the right lateral ventricle. There were subpleural petechiae. No clots were found in the heart or in any of the great vessels or cerebral sinuses. The intima of the aorta and pulmonary artery was moderately icteric. The liver showed severe fatty changes. All other organs appeared normal.

Histology. In the right occipital lobe a large area of brain tissue was necrotic and replaced by red blood corpuscles and débris. In the region of the posterior horn of the right lateral ventricle the blood vessels were distended and engorged with red blood corpuscles, there being numerous punctate haemorrhages. The erythrocytes were not confined to the adventitial spaces of Virchow-Robin but were also seen within the adjacent brain tissue. There was a distinct proliferation of glia cells in the subependymal layer. The ependyma itself was normal. Occasionally polymorphs and round nucleated cells were seen in greater numbers within a small haemorrhage.

The heart muscle fibres showed granular degeneration, the striation being very indistinct. In the liver were severe fatty changes of infiltrative type mainly in the periphery of the lobuli. The Malpighian bodies of the spleen were atrophic, the pulp was hyperplastic and cellular, the majority of the cells being large mononuclears. The venous sinuses were narrow and often empty. The kidney showed cloudy swelling mainly of the first convoluted tubules.

FAMILY HISTORY. In December, 1942, the parents were interviewed. They now had a second child aged four months who was healthy and thriving. His blood was examined which gave a clotting time of 1 minute 15 seconds, platelets 305,000 per c.mm., fibrinogen $0.22 \mathrm{gm}$. per cent.

The father and mother were the youngest and eldest respectively of families which were healthy, showing no tendency to bleed or bruise easily. The two eldest members on the father's side had both died at the ages of fifty-three and forty-one of cerebral haemorrhage. The elder had hypertension.

The father's blood, apart from a reduction in the platelets $(150,000$ per c.mm.), showed no abnormality. Blood fibrinogen was $0.31 \mathrm{gm}$. per cent. The blood pressure was $130 / 85 \mathrm{~mm}$. Hg.

The father's brother aged thirty-six was also examined. He showed a normal blood count, a blood fibrinogen of $0.26 \mathrm{gm}$. per cent. and had a blood pressure of $140 / 85 \mathrm{~mm}$. $\mathrm{Hg}$.

The mother's platelets were reduced to 120,000 per c.mm. and her fibrinogen was $0.15 \mathrm{gm}$. per cent. The blood, nevertheless, showed no other abnormality, the bleeding time being 34 seconds, clotting time 2 minutes, prothrombin time 40 seconds (control 30 seconds). The platelets and fibrinogen were repeated three weeks later and were 220,000 per c.mm. and $0.15 \mathrm{gm}$. per cent. respectively. 
Case 2. History. D. C., a female, was born one month prematurely. weighing $6 \mathrm{lb}$.

The labour was normal, but the baby never seemed satisfactory, vomiting several times a day. On the te.nth day she became jaundiced and although the depth of colour fluctuated, it gradually deepened. The urine became dark and the stools pale. At the age of two months two bruises were noticed on her knees. The following day she began to have bouts of screaming lasting intermittently for twelve hours. She then became weaker and was admitted (April 23, 1942).

Examinatiox. A deeply jaundiced undernourished infant with slow grunting respiration. Pulse 72. There were twitching movements of the right arm and leg. the right side of the face being drawn up. The right eye showed coarse nystagmoid movements laterally and had a small reactive pupil. The left eye remained motionless in the mid line, the pupil was dilated and fixed, the evelid was kept closed.

The fontanelle was tense. The liver edge was one to two finger breadths below the costal margin. Two bruises were present over the right knee.

The cerebrospinal fluid was blood stained.

BLOOD PICTLRE.

Haemoglobin 84 per cent. Platelets $\mathbf{2 8 0 . 0 0 0}$ per c.mm.

Red blood cells 3,720.000 per c.mm. Reticulocytes $5 \cdot 4$ per cent.

White blood cells 14.500 per c.mm. Bleeding time 3 minutes 10 seconds.

Clotting time: No clot after 24 hours.

Prothrombin time: No clot after 30 minutes (control 25 seconds).

Blood fibrinogen: None found. Besides the Wu method for fibrinogen estimation, heating at $56 \mathrm{C}$., ammonium sulphate precipitation and the addition of fresh normal serum have been used.

60 c.c. of maternal blood were given intravenously, with 1 c.c. kapilon intramuscularly. The following day the prothrombin time was 30 seconds (normal control 20 seconds). The jaundice persisted, the liver became larger and firmer, the stools were persistently pale and contained no bile pigments [examined for bilirubin by the method of Malloy and Evelyn (1938), for stercobilinogen by a combination of the methods of Watson (1931) and Heilmeyer (1933) with omission of the ether extraction and for stercobilin and other pigments by spectroscopic and fluoroscopic examination of an acid-alcoholic stool extract after addition of zinc alcohol]. The patient died on August 1, 1942.

While in hospital further blood fibrinogen and 'prothrombin time ' estimations were made on the following dates, control figures being given in brackets.

274 42. Prothrombin time 25 seconds $(20$ seconds).

29442 . Fibrinogen $0.29 \mathrm{gm}$. per cent.

7542 . Prothrombin time 20 seconds $(20$ seconds). Fibrinogen 0.34 gm. per cent.

29742 . Prothrombin time 45 seconds 123 seconds). Fibrinogen 0.34 gm. per cent.

ALTOPSY. A rather small, very hard dark green liver was found with the typical appearance of biliary cirrhosis. The gall bladder was normal in size, collapsed and contained a small amount of colourless fluid. The common bile duct was completely obliterated, the cystic and hepatic ducts were obliterated in their distal but patent in their proximal portions. The thymus was transformed into a soft haemorrhagic mass weighing $15 \mathrm{gm}$. There was an occasional haemorrhagic suffusion of the submucosa in the small intestine. Clotted blood, yellow pigment and thin spider-web-like mambranes yellowishred in colour were found on the internal surface of the dura mater over almost the whole of the left side of the vertex. The lateral ventricles were dilated. On the right side pus was found in the middle ear and there was necrosis of a considerable part of the petrous portion of the temporal bone.

Histology. The liver showed a considerable proliferation of the cellular connective tissue in the interlobular spaces. The trabecular arrangement of the liver cells around the central vein was preserved in most lobuli, but of ten the connective tissue was seen growing into the lobuli. separating and isolating groups of cells. The bile ducts were proliferated and dilated. containing numerous bile thrombi. Except for the haemorrhage in the thymus nothing noteworthy was found in the other organs.

For fibrinogen, globulin and albumin estimations the method of Wu (1922) was used. for calcium estimation the method of Kramer and Tisdall (1921) and for ' prothrombin time' MacPherson, McCallum and Haultain's modification of Quick's onestage method (1940) were employed.

\section{Discussion}

There can be little doubt that a deficiency of blood fibrinogen may be either congenital or acquired. Case 1 is considered to be an example of the former. Case 2 of the latter.

Characteristic of the congenital type is the tendency to bleed from birth. oozing from the umbilical stump being common. In those cases which survive, the bleeding is periodic. whereas the fibrinogen remains low or even absent. To explain the periodicity of symptoms, the existence of a second factor has been postulated. Rabe and Salomon thought there must be some change in the vascular permeability.

Several authors commented on the association of thrombopenia with fibrinogenopenia. A low platelet count per c.mm. was reported by:

Opitz and Frei (1921) 114.000.

Opitz and Silberberg (1924) 14,000.

MacFarlane (1938) 110,000.

Schönholzer (1939) 84,000 on one occasion

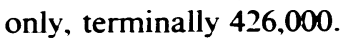

Glanzman et al. (1940) 35,000 rising to 275,000 with cessation of bleeding.

The figure of 50,000 in Case 1 may have contributed to the haemorrhagic tendency. Although the majority of the above figures are not low enough to explain the haemorrhagic manifestations per se, the thrombocytopenia may play a rôle in association with the fibrinogen deficiency.

Higher counts were found $(296,000)$ by Wolff (1936) and (190,000) by Knauer (1927). The second case here reported had $\mathbf{2 8 0 , 0 0 0}$ platelets at the time of bleeding.

Opitz and Frei as well as Schönholzer showed that the platelets in their cases contained thrombokinase (more exactly Bordet's cytozyme). Functional platelet tests as described by Baar and Székély (1929), 
by Morawitz and Jürgens (1930), by Jürgens and Naumann (1932), and recently by Wright (1941) were not used by these authors. That occasionally a functional deficiency of platelets without thrombocytopenia may be a cause of haemorrhagic disease of the newborn has been recently shown by one of us (Baar, 1941).

With regard to the co-operation of other factors in producing clinical symptoms and pathological coagulation in cases of fibrinogenopenia, Case 1 is of particular interest. The fibrinogen level, although definitely low, was higher than in any of the fibrinopenic cases described in the literature. Hatz and Koranyi (1938) have reviewed all papers dealing with normal fibrinogen values up to 1938 . In their table, figures obtained by refractometric or nephelometric methods may be disregarded as not sufficiently accurate. If only gravimetric and Kjeldahlometric methods are taken into account, 0.20 to $0.48 \mathrm{gm}$. per cent. (one figure 0.60) may be considered as the normal range for plasma fibrinogen. Peters and van Slyke (1931) give the figure 0.2-0.4 gm. per cent., Rappaport (1935) 0.2-0.4 gm. per cent. and Bendien and Snapper (1931) 0.25-0.40 gm. per cent. as normal. Gram (1922) and Starlinger and Windans (1928), who reported the largest series of normal and pathological cases consider 0.28 to $0.38 \mathrm{gm}$. per cent. and 0.22 to $0.36 \mathrm{gm}$. per cent. respectively as the normal range. Little has been done on the normal plasma fibrinogen of young babies. Crane and Sanford (1936) found, in an investigation on 131 infants aged one to ten days, a range of 0.22 to $0.36 \mathrm{gm}$. per cent. for the first and 0.33 to $0.50 \mathrm{gm}$. per cent. for the tenth days. From figures obtained in the Birmingham Children's Hospital by Kjeldahlometric and colorimetric methods it is believed that the plasma fibrinogen of young babies is within the normal adult range. Jürgens and Trautwein (1930) considered 0.15 to $0.12 \mathrm{gm}$. per cent. as the 'critical level' for fibrinogen below which the blood remained incoagulable. Risak (1935) rightly objected to this statement, reporting cases with lower fibrinogen figures and only moderately prolonged clotting time. The present case had a fibrinogen level of $0.11 \mathrm{gm}$. per cent. and yet the blood behaved like that of the severest fibrinogenopenia. There was no coagulation within four hours and only a tiny coagulum floating in the liquid blood some time afterwards. Such a clotting abnormality is never met even in the severest cases of prothrombin deficiency of the newborn. A prothrombin time of 4 to 6 minutes in the one-stage method indicates an extremely severe 'hypoprothrombinaemia,' and when once coagulation takes place the clot is of a perfectly normal appearance. In haemophilia, on the other hand, where a clotting time of several hours is often observed, the addition of a small amount of tissue extract is sufficient to correct the abnormality.

A calcium deficiency can not be responsible for the extremely long clotting time, the level being $8.1 \mathrm{mgm}$. per 100 c.c. and $9.6 \mathrm{mgm}$. per 100 c.c. respectively in the present cases, $10.5 \mathrm{mgm}$. per 100 c.c. in MacFarlane's and 12.0 mgm. per 100 c.c. in Schönholzer's cases. MacFarlane found that on addition of fibrinogen to his patient's blood, the clotting time was still delayed as compared with a control. As he also proved that the amount of antithrombin was not increased, this must have been due to a diminished formation of thrombin, either from lack of prothrombin or of thrombokinase. Further support to this view is obtained from Schönholzer's observation that arrest of haemorrhage was achieved by the transfusion of a quantity of blood sufficient only to raise the fibrinogen level to $0.06 \mathrm{gm}$. per cent. From the data which Knauer gives, and assuming the blood he transfused contained $\mathbf{0 . 3} \mathrm{gm}$. per cent. of fibrinogen, it is estimated that relief from symptoms occurred with a fibrinogen level of 0.066 gm. per cent. Similar results were obtained in the second case here reported, when after blood transfusion the plasma fibrinogen was calculated to be about $0.05 \mathrm{gm}$. per cent.

If, in the first case where the blood fibrinogen was $0.11 \mathrm{gm}$. per cent. the prothrombin time were prolonged proportionally to the deficiency of fibrinogen, it should have been in the order of 60 seconds, providing all other factors necessary for clotting were present in adequate amounts. If it is assumed that there is no increase in antithrombin, then the greatly prolonged clotting time in the first case must be associated with another factor. As the blood calcium was normal and the thrombokinase was added in adequate amount, a quantitative or qualitative deficiency in the prothrombin is to be assumed. A direct estimation of the prothrombin level by a two-stage method was unfortunately impossible, as the baby died before a fresh fibrinogen solution could be prepared.

To throw some light on the discrepancies between the degree of fibrinogenopenia and the prolongation of clotting time it was decided to make some experiments in which constant amounts of fibrinogen were tested against various dilutions of thrombin or optimally incubated recalcified prothrombin solutions and vice versa. The fibrinogen solutions were prepared according to Herbert (1940) and purified by dialysis. The solution contained $0.4 \mathrm{gm}$. per cent. fibrinogen. Prothrombin and thrombin solutions were also prepared by the methods described by Herbert, the clotting time, however, was estimated by inclining the tube and two drops of fibrinogen solution were used instead of one. All estimations were made in a water bath at $37^{\circ} \mathrm{C}$. The results of three experiments out of ten are reported below.

Experiment 1. Undiluted thrombin solution was added to increasing dilutions of fibrinogen in normal saline:

Fibrinogen diluted $1 / 1$ produced a clot in 80 seconds. *

Fibrinogen diluted $1 / 2$ produced a clot in 125 seconds.

Fibrinogen diluted $1 / 3$ produced a clot in 165 seconds.

- The thrombin solution was prepared from stored plasma which probably accounts for the comparatively long clotting time. 
Fibrinogen diluted $1 / 4$ produced a clot in 175 seconds.

Fibrinogen diluted 15 floccules only in 243 seconds.

Fibrinogen diluted 16 floccules only in 285 seconds.

Experiment 2. Increasing dilutions of thrombin solution in normal saline were added to undiluted fibrinogen and to fibrinogen diluted 10 times.

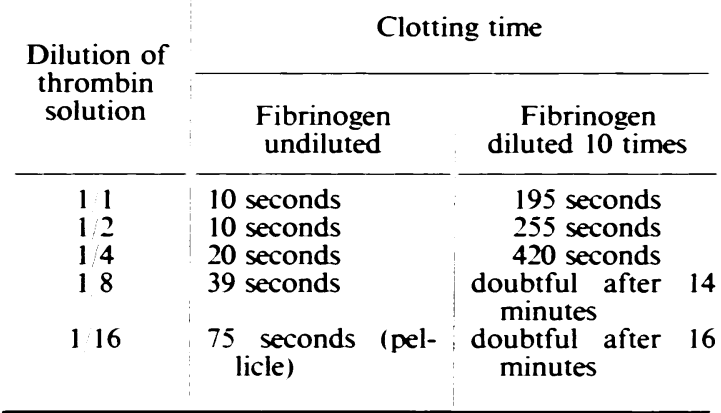

Experiment 3. To increasing dilutions of fibrinogen, thrombin has been added, which was obtained from 100 times and 200 times respectively diluted plasma optimally incubated after addition of calcium and brain extract.

\begin{tabular}{|c|c|c|}
\hline \multirow{2}{*}{$\begin{array}{l}\text { Dilution of } \\
\text { fibrinogen }\end{array}$} & \multicolumn{2}{|c|}{ Clotting time } \\
\hline & $\begin{array}{l}\text { Plasma diluted } \\
100 \text { times }\end{array}$ & $\begin{array}{c}\text { Plasma diluted } \\
200 \text { times }\end{array}$ \\
\hline $\begin{array}{l}0 \\
1 / 1 \\
1 / 2 \\
1 / 3 \\
1 / 4\end{array}$ & $\begin{array}{l}30 \text { seconds } \\
40 \text { seconds } \\
40 \text { seconds } \\
60 \text { seconds (soft) } \\
80 \text { seconds (soft) }\end{array}$ & \begin{tabular}{|l|}
30 seconds \\
30 seconds \\
30 seconds (soft) \\
70 seconds (soft) \\
210 seconds (partial
\end{tabular} \\
\hline $1 / 5$ & $\begin{array}{l}120 \text { seconds (par- } \\
\text { tial and floating) }\end{array}$ & indefinite \\
\hline
\end{tabular}

These experiments show that while within a certain range of dilutions the clotting time is roughly proportional to the concentration of the reacting substances, a dilution of thrombin to $1 / 2$ may be without influence on the clotting time when the fibrinogen solution is undiluted, but cause a marked increase in the clotting time when a 10-times diluted fibrinogen solution is used. A dilution of fibrinogen to $1 / 4$ prolonged the clotting time $2 \frac{1}{2}$ times when a prothrombin dilution 1:100 was used but 7 times when the latter was $1: 200$.

This limited compensation of a deficiency in one coagulation factor by another is, in principal, not new. Ziffren, Owen, Hoffman and Smith (1939) stated that ' when prothrombin falls below 30 to 50 per cent. a bleeding tendency appears. Above this level blood clots at a normal rate (6 to 10 minutes) suggesting that other factors vary to compensate for any prothrombin deficiency which may exist. Klinke (1938), who studied the kinetics of the thrombin-fibrinogen reaction, found a good agreement with a formula suggesting a self-accelerated enzymatic process only when both thrombin and fibrinogen were used in higher dilutions. It is, therefore, concluded that similarly as in the haemostatic mechanism, where one deficient factor may be compensated by another, there is also a mutual compensation among the factors concerned with one part of this mechanism, the coagulation of blood.

From these findings a serious objection arises against all one-stage methods of prothrombin estimation. It has to be realized that such a method gives only information about the clotting time in the presence of an excess of thrombokinase. The other known factors are fibrinogen, prothrombin and calcium. Any of these if deficient may cause a prolonged ${ }^{*}$ prothrombin time ${ }^{*}$ and fibrinogen being in excess may mask a moderate prothrombin deficiency. Fibrinogenopenia is, however, a rare condition and hypocalcaemia almost never causes a disturbance of coagulation. For routine estimations therefore the one-stage method will remain a useful measure of quantitative or qualitative prothrombin deficiency. More important is a therapeutic conclusion. It has recently become a habit to consider haemorrhagic disease of the newborn and hypoprothrombinaemia as synonymous. Vitamin $\mathrm{K}$ is used routinely and artificial feeding of the newborn has been recommended. Sanford et al. (1942), however, in a study of 1,600 newborn babies showed that, although the administration of vitamin $K$ to the baby or to the mother before birth, raised the prothrombin level, it did not affect the frequency of haemorrhagic manifestations. Apart from the fact that the clinical results are not nearly as dramatic as the return of the "prothrombin time" to normal figures. the present observations give support to the view put forward in a leading article of the Lancet (1940), that the well established treatment by blood transfusions should not be abandoned in favour of vitamin $\mathrm{K}$ therapy.

The interrelationship between the various factors concerned with blood clotting is seen acting in a different manner in chronic pathological states in which a deficiency of one factor may be compensated for by another. This is seen in two cases of constitutional fibrinopenia in adults quoted by Risak, when in spite of a low blood fibrinogen $10.018 \mathrm{gm}$. per cent.), the clotting time was normal in one case and only slightly raised (4 to 12 minutes) in the other.

Case 1 is considered as congenital fibrinogenopenia because the haemorrhagic manifestations started soon after birth with oozing from the umbilical stump, the liver damage was of a common type and the mother had a low fibrinogen. Case 2 was obviously an acquired and transient afibrinogenia in a case of congenital obliteration of the bile ducts and biliary cirrhosis of the liver.

The lowering of blood fibrinogen as a secondary 
manifestation naturally lead to speculation as to the site of its formation.

The role of the liver in the formation of fibrinogen is fairly well established. This was first suggested by Corin and Aniseaux (1894) who found disappearance of plasma fibrinogen in phosphorus intoxication. Isaac-Krieger and Hiege (1923) found fibrinogenopenia in diffuse liver diseases, often in icterus simplex and regularly in acute yellow atrophy. The significance of these findings is, however, somewhat shaken by the findings of Jacobi (1900), who demonstrated that the blood in phosphorus intoxication has fibrinolytic properties. Doyen's (quoted by Isaac-Krieger and Hiege, 1923) statement that the blood from the hepatic vein contains more fibrinogen than the peripheral venous blood and the experiments of Mann and Magath (1922). showing the disappearance of fibrinogen in hepatectomized dogs, can scarcely be explained in any other way than by accepting the liver as one site of fibrinogen formation. Glanzmann, Steiner and Keller (1940), from the consideration of their own case and those of Wolff, and Opitz and Silberberg, were of the opinion that acquired fibrinogen deficiency was associated with liver damage. In taking this view they ignored the cases of Knauer, and Jürgens and Trautwein and disregarded the opinion of Schönholzer, that in man no toxin acts solely on the liver. The case of Jürgens and Trautwein, although occurring in an adult, is important in suggesting the bone marrow as a site for fibrinogen formation. Müller (1905) found that after injections of dead bacteria the fibrinogen content of the bone marrow was greater than that of the blood. Keilhack. quoted by Jürgens (1938) estimated the fibrinogen of the red bone marrow of rabbits after washing out the blood and found it to be $1.095 \mathrm{gm}$. per cent. as compared with 0.296 gm. per cent. plasma fibrinogen. Jürgens (1938) mentions that

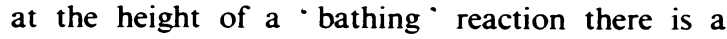
reticulocytosis associated with an increase of plasma fibrinogen. This, in association with the high plasma globulin figures in multiple myelomas, with the fibrinogenopenia in panmyelophthisis (aplastic anaemia) and with the observation of Jürgens and Trautwein in a case of acquired fibrinogenopenia, is suggestive of the bone marrow being a second site of fibrinogen formation. Experimental support for this conception was supplied by Jürgens and Gebhardt (1934) who found a rise in blood fibrinogen in dogs with Eck-fistula at the height of meat intoxication and in hepatectomized geese after pyrifer injections.

It is, therefore, not justifiable, in a case of liver disease and fibrinogenopenia, to assume without other evidence that the liver disease is the cause of the fibrinogenopenia. The case of congenital obliteration of the bile ducts is instructive on this account. After restoration of the fibrinogen to normal, the level remained constant until death three months later in spite of what must have been progressive liver damage. This led to estimations being made on cases of suspected hepatic disease.
In the following cases, autopsy confirmed the diagnosis:

\begin{tabular}{|c|c|c|c|c|}
\hline Case & Disease & $\begin{array}{l}\text { Age at } \\
\text { death }\end{array}$ & $\begin{array}{c}\text { Fibrinogen } \\
\text { estimated } \\
\text { No. of } \\
\text { days } \\
\text { before } \\
\text { death }\end{array}$ & $\begin{array}{l}\text { Plasma } \\
\text { fibrinogen } \\
\text { gm. per } \\
\text { cent. }\end{array}$ \\
\hline $\begin{array}{l}\text { P.W. } \\
\text { G.C. } \\
\text { R.B. }\end{array}$ & $\begin{array}{l}\text { Icterus gravis } \\
\text { Icterus gravis } \\
\text { Congenital obliteration } \\
\text { of bile ducts }\end{array}$ & $\begin{array}{l}1 \text { day } \\
5 \text { days } \\
4 \frac{1}{2} \text { months }\end{array}$ & $\begin{array}{r}0 \\
26\end{array}$ & $\begin{array}{l}0.46 \\
0.42 \\
0.48\end{array}$ \\
\hline C.C. & $\begin{array}{l}\text { Congenital obliteration } \\
\text { of bile ducts }\end{array}$ & 4 months & 15 & 0.44 \\
\hline $\begin{array}{l}\text { M.R. } \\
\text { N.T. }\end{array}$ & $\begin{array}{l}\text { Syphilis } \\
\text { Acute yellow atrophy }\end{array}$ & $\begin{array}{l}2 \frac{1}{2} \text { months } \\
10 \text { years }\end{array}$ & $\begin{array}{l}16 \\
12\end{array}$ & $\begin{array}{l}0 \cdot 40 \\
0 \cdot 40\end{array}$ \\
\hline
\end{tabular}

It is seen that severe liver disease may be without effect on the plasma fibrinogen.

Formation of fibrinogen in the liver and in the bone marrow is fairly well established. Damage of the bone marrow would also explain the comparatively frequent association of fibrinogenopenia with thrombocytopenia. A generalization, however, like that of Spadolini (1931-2), Campellone (1935), Leszler and Pauliczky (1933), Held and Behr (1934) and Risak (1935), who consider the whole reticulo-endothelial system as concerned with the formation of fibrinogen, is based more on speculation than fact.

Finally, one observation in the second case deserves some attention. A complete absence of fibrinogen was followed by normal amounts shortly after blood transfusion and injection of vitamin $K$. This may be a coincidence but Glanzmann et al. also observed a rise in fibrinogen after treatment which included vitamin $K$. The blood fibrinogen was, therefore, estimated over a long period in eight guinea-pigs. After a pre-experimental period four were injected with vitamin $\mathrm{K}$. Following a further period to ensure that there was no alteration in the fibrinogen levels, all the animals were poisoned with phosphorus and the injections of vitamin $\mathbf{K}$ continued. No significant difference was observed between the two groups. This negative result is not conclusive as sufficient vitamin $K$ may have been present in the food of both groups.

\section{Summary}

One case of congenital fibrinopenia and one case of transient afibrinogenia are described and the literature reviewed.

The relationship between prothrombin and other coagulation factors is discussed and experiments concerning this question reported.

The site of fibrinogen formation is discussed.

Experiments on the influence of vitamin $K$ on fibrinogen formation were not conclusive.

Thanks are due to Dr. A. V. Neale for permission to publish the cases under his care and to Miss Finch and Miss Tonks of the Biochemical Dept. for the estimations.

Addendum.-Recently an additional case of congenital fibrinogenopenia was observed in an infant 
with haemorrhagic disease of the rewborn in which the findings gave support to the conception of a compensatory method in blood coagulation. On admission, the one-stage method of prothrombin estimation yielded no clotting in two hours. The fibrinogen level was 0.12 gm. per cent. After a blood transfusion and two injections of vitamin $\mathbf{K}$ the prothrombin time was sixty seconds but the fibrinogen remained unaltered.

\section{REFERENCES}

Baar. H. S. (1928). In Baar, H., and Stransky, E., Die klinische Haematologie des Kindesalters, Leipzig.

- - (1934). Wien. klin. Wischr., 47, 1039.

- (1941). Lancet, 2, 775.

_- and Székély, L. (1929). Z. Kinderheilk., 48, 31.

Bendien. W. M., and Snapper, I. (1931). Biochem. Z. $235,14$.

Breckoff. E. (1924). Mschr. Kinderheilk., 28, 232.

Campellcne, P. (1935). Klin. Wschr., 14, 643.

Corin and Aniseaux (1894). Quoted by Jacobi.

Crane. M M.. and Sanford. H. N. (1936). Amer. J. Dis. Child., 51, 99.

Frank. E. (1925). In Schittenhelm, A., Handbuch der Krankheiten des Blutes und der Blutbildenden Organe, Berlin, 2.

Glanzmann, E., Steiner, H., and Keller, H. (1940). Schreiz. med. Wschr.. 70, 1243, and 1261.

Gram. H. (1922). Quoted by Starlinger and Windans.

Hatz, E. B., and Koŕanyi, A. (1938). In Bennhold, H. H., Kylin, E., and Rusznyák, S., Die Eiveisshörper des Blutplasmas, Leipzig.

Heilmeyer, L. (1933). Medizinische Spektrophotometrie, Jena.

Held, A.. and Behr, C. H. (1934). Klin. Wschr., 13. 1120 .

Herbert. F. K. (1940). Biochem. J., 34, 1554.

Isaac-Krieger, K., and Hiege, A. (1923). Klin. Wschr., 2, 1067

Jacobi, M. (1900). Hoppe-Seyler Z., 30, 174.

Jürgens, R. (1938). In Bennhold, H. H., Kylin, E., and Rusnyák, S., Die Ein'eisskörper des Blutplasmas, Leipzig.

and Gebhardt. F. (1934). Arch. exper. Path. Pharmak., 174, 532. Med., 172, 248.
Jürgens, and Trautwein, H. (1930). Ibid., 169, 28.

Klinke, K. (1938). In Bennhold, H. H.. Kylin, E., and Rusznyák, S., Die Eineisskörper des Blutplasmas. Leipzig.

Knauer, H. (1927). Jb. Kinderheilk.. 118, 1.

Kramer. B., and Tisdall, F. F. (1921). J. biol. Chem., 47,475 .

Leading article (1940). Lancet, 1, 650.

Leszler, A., and Pauliczky, L. (1933). Z. ges. exp. Med., 91, 86.

MacFarlane, R. G. (1938). Lancet, 1, 309.

MacPherson, A. I. S.. McCallum, E., and Haultain, W. E. T. (1940). Brit. med. J., 1, 839.

Magnus, G. (1924). Arch. klin. Chir.. 130, 237.

Malloy, H. T., and Evelyn, K. A. (1938). J. biol. Chem., 122, 597.

Mann, F. C.. and Magath, T. B. (1922). Arch. intern. Med., 30, 73.

Morawitz, P., and Jürgens, R. (1930). Münch. med. Wschr., 2001.

Müller, P. T. (1905). Quoted by Jürgens (1938).

Opitz. H., and Frei, M. (1921). Ib. Kinderheilk., 94, 374.

_.., and Silberberg, M. (1924). Klini. Wischr., 3, 1443.

Peters, J. P., and van Slyke, D. D. (1931). Quantitative clinical chemistri; London.

Rabe, F., and Salomon, E. (1920). Disch. Arch. klin. Med. . 132, 240.

Rappaport, F. (1935). Mikrochemie des Blutes., Wien.

Risak, E. (1935). Z. Klin. Med., 128, 605.

Roskam, J. (1921). C. R. Soc. Biol. Paris, 85, 18 and 733.

Sanford, H. N., Gasteyer, T. H., and Wyatt, L. (1932). Amer. J. Dis. Child., 43, 58.

Shmigelsky, I., and Chapin, J. M. (1942). J. Amer. med. Ass., 118, 697.

Schönholzer, G. (1939). Dtsch. Arch. Klin. Med., 184, 496.

Spadolini, I. (1931-2). Arch. Fisiol., 30, 241.

Starlinger, W., and Windans, E. (1928). Z. ges. exp. Med. 60, 138, 160, 185, and 208.

Watson, C. J. (1931). Arch. intern. Med., 47, 698.

Wolff, J. (1936). Jb. Kinderheilk., 148, 33.

Wright, H. P. (1941). J. Path. Bact., 53, 255.

Wu, H. (1922). J. biol. Chem., 51, 33.

Ziffren, S. E., Owen, C. A., Hoffman, G. R., and Smith, H. P. (1939). Proc. Soc. exp. Biol., N.Y., 40, 595. 